\title{
Service Biophysical Earthquake Prediction (Results and Prospects)
}

\author{
V. M. Inyushin', K. N. Aldibekova'2, Sh. N. Aldibekova'3 , A. Baysakalova² \\ ${ }^{1}$ Kazakh National University Named after Al-Farabi, Almaty, Republic of Kazakhstan \\ ${ }^{2}$ Zhetisujski State University, Taldykorgan, Republic of Kazakhstan \\ ${ }^{3}$ Kazakh State Women Pedagogical University, Almaty, Republic of Kazakhstan \\ Email: aldibekova-gulden@mal.ru
}

Received 6 June 2014; accepted 26 January 2016; published 29 January 2016

Copyright (C) 2016 by authors and Scientific Research Publishing Inc.

This work is licensed under the Creative Commons Attribution International License (CC BY).

http://creativecommons.org/licenses/by/4.0/

(c) (i) Open Access

\begin{abstract}
Analysis of the data suggests that the biophysical radiophysical sensing future earthquake epicenters is a promising direction for the medium-term and short-term forecasting of seismic events. We believe that it is necessary to create an international network of seismic monitoring biophysical for all seismically active areas of the globe. Information about biophysical precursors of earthquakes should be accumulated in the computer center, and operating information transmitted to all peripheral seismic monitoring station biophysical and services Ministry of Emergencies. In conclusion, I emphasize the value of such a centralized system of control over the "breath" of the Earth for the prevention and the prevention of industrial accidents in the mines, road transport, large power plants, etc.
\end{abstract}

\section{Keywords}

Bioplasma, Geoplasma, Geoanomalies, Fluctuation, Hibernation, Harbingers, The Epicenter, Seism

\section{Introduction}

Credible medium-term and operational methods of earthquake prediction was not offered in the world of science and the practice. This was primarily evidenced by a bad experience midterm operational forecasting strong earthquake in Kobo (Japan, 1995) which led to great loss of human life, over 5000 people.

Japanese seismic stations could not answer questions from the public: if they wait a few hours of aftershocks. Such uncertainty operational forecasting creates grounds for panic disorder population of the city, causing exacerbation of psychosomatic diseases. I do specifically focus on this aspect of the problem, because some part of specialists in seismic-resistant construction is believed that the design and operational methods of the me- 
dium-term forecast does not need a futile exercise. I reject this view and believe that we need to triple efforts in research projects aimed at finding reliable harbingers of future earthquakes. Population seismically dangerous areas of the media should know what "weather underground" they can expect in the coming hours, days and months.

Kazakhstan School biophysicists for 40 years held a fundamental study on the fifth state of matter-bioplasma and its interaction with plasma-geoplasma rocks [1]. First in 1978, March 24 at 20 pm Almaty time were recorded unusual fluctuations of the parameters in the form of plants bioplasma changes photon emission, “dance”, etc. biopotentials before the strong earthquake Zhalanash-Tyubskim (150 km east of Almaty). The earthquake took place at 4:00 am on March 25. The earthquake in the epicenter was more than 7 points in the city-to 6 points. Was heard powerful underground buzz, strong vibrations were observed in almost all areas of the city [2]. Most of the urban population overlooked the street.

In a world, biophysical earthquake precursors first discovered it. It is known that in the 70s of the last century, a prominent scientist and naturalist zoologist P. I. Marikovskiy noticed that many insects and animals change their behavior long before the earthquake. His idea received implementation in China, when the behavior of animals managed to forecast earthquake and save more than five hundred thousand people. Subsequent attempts to predict the earthquake in China and Japan via zoopovedencheskih tests have failed. I believe that this is due to the fact that it is necessary to observe the animals in their natural environment without any external intervention , which is so rich in our reality today (acoustic noise, electrostatic interference, extreme weather changes with symptoms of sudden warming or cooling, and changes in solar activity, etc.).

\section{Zhivye Organisms Have Supersensitive Receptors, Which Are Able to Catch the Slightest Changes in the Bowels of the Earth before the Earthquake}

Attempting to put the animals in hothouse conditions: cells, terrariums etc.- - for the same reasons as not yielded positive results. However, despite all the shortcomings of the method, it must be taken into account, and should be used as an additional a precursor of earthquakes along with dozens of others. There is no doubt that the more diverse range of precursors, the higher the accuracy of medium-term and operational forecasting of earthquakes. There is no doubt that living organisms have supersensitive receptors, which are able to catch the slightest changes in the bowels of the earth before the earthquake.

Of particular value in this regard are plants that have geotropism (feel the gravitational field of the Earth) and are very sensitive to geoanomalies that change shape the development of the trunk, branches, etc. We have chosen the plant tissue of woody plants as indicators of future earthquakes and transformed their physiological processes in the state of suspended animation. In this status, the plant tissues are particularly sensitive to changes in the structure electrically polarized rocks. First of all, we mean the spin structure of the electric charges, their clusters are not recorded by the most sensitive instruments. Of particular importance is the change in the structure of the physical real vacuum that has its own specifics in geoanomalnyh spaces. Unfortunately, biophysics vacuum and its structure are very poorly studied and our knowledge is mainly represented by numerous hypotheses that are not scientifically sound thermodynamic foundation. That is why using seismic danger indicator (ISO-3), wherein the receptor is in a state of suspended animation biomass is isolated from contact with the atmosphere, and electromagnetic fields that can detect changes in the electrical parameters of the charges and the particles of material in the earth's crust of the vacuum according to certain channels (geoanomalies) at a distance of several thousand kilometers from the earthquake epicenter.

So we were able to carry out a very clear outlook for the electric polarization vector here in Almaty, and the future of the earthquake occurred in Turkey, Iran, India, Russia and Japan. So for two months before the earthquake in the epicenter of 9 - 10 in the Central Altai (Russia), we recorded electrical field vector in Almaty in a northerly direction. Such great sensitivity biophysical indicators, which proved to huge statistical data from 1978 to 2008. During this period, was successfully predicted 52 of the 60 earthquakes that occurred within Almaty up to two thousand kilometers. Eight medium-term forecast of earthquakes were predicted with an error of 1.5 - 2 days, the operational forecast for 5 - 8 hours. In these cases, the earthquake occurred later than predicted. Medium-term earthquake prediction biophysical published in 3 - 4 months. Operational data is transmitted every day of the alleged duty seismic situation in the city Department of Emergency Almaty. Provides information about the alleged strength of the earthquake, the epicenter of the localization of the future and the direction of the seismic impact of Almaty (south, east, west, north). 


\section{Sluzhba Biophysical Earthquake Prediction}

Service biophysical earthquake prediction has the following structure:

1) Central Station biophysical earthquake prediction is in midstream Kargali (Karasay district, Almaty region). This is where tectonic faults are from the west, southwest, south and south-east. Such tectonic faults form a "nodal" points, which are located bioindicators. There are regular state geoanomalies biophysical monitoring, which are particularly numerous in the region of the tectonic faults. Wood bioindicators occupy an area of 10 hectares. In fact, the collection of woody indicators is a biosensor that is able to "feel" changes in the structure geoplasma before the earthquake. In the laboratory building station installed juggernaut bioindicator from which readings are taken electropotential, current bio-plasma interaction with wood geoplazmay rocks.

2) Daily data is recorded in a logbook. Bioindicators have great sensitivity in the northeast, east and south of the city of Almaty. Figure 1 shows a graph of the electric potential geoplasma before Altai strong earthquake that occurred on September 27, 2003. The epicenter was located at a distance of over $1200 \mathrm{~km}$ from Almaty. First signs of instability geoplasma electrical potentials were recorded at the beginning of June 2003 in the south-eastern ranges of the Altai, and in the foothills of Trans-Ili Alatau. The amplitude of the electric potential in the direction of his fall was registered 16 days before the seismic event, as evidenced by the graph in Figure 1.

Selected for the analysis of temporal changes Biotok record that was recorded by means of electrodes implanted in the tree (poplar, age 50.5 years), the device SCH4315 observation point at the biological station KazNGU and the observation point at the biological station in Serebryansk (ASD). Time of observation 1996. December and March 2000 and 2001. Time series records were entered into the computer, edited and digitized with a time step 1 hour for time series recorded at the biological station in KazNGU and 1 day for registered Serebryansk. (EBA). If biostation KazNGU leads seismological observations of the Alma-Ata polygon, the biological station in Serebryansk cover almost the entire East Kazakhstan seismic areas, which includes the Altai mountain located on the territory of Russia. Radius determination harbingers of $500 \mathrm{~km}$. Common

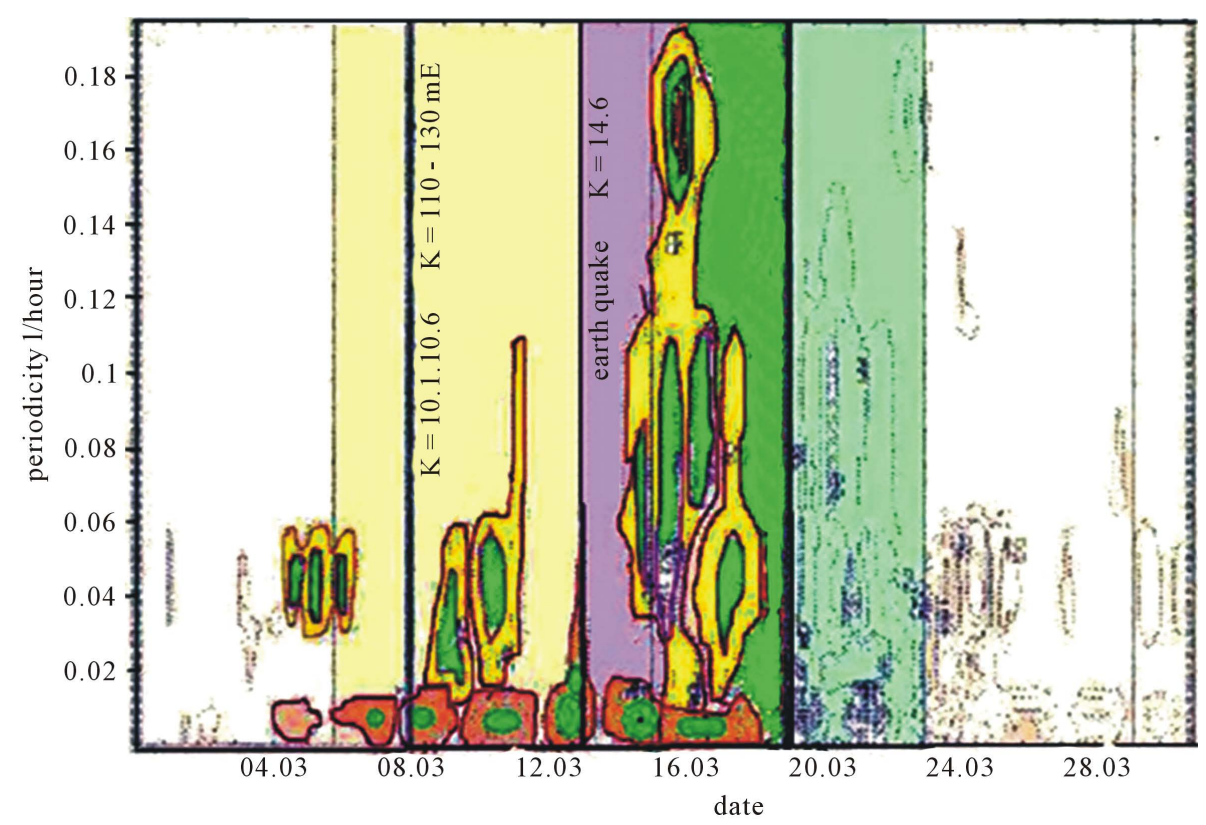

Figure 1. On shows the change in A (f, t) for 2 mart $1996 \mathrm{~g}$. Allocated anomaly bioplasma Virtually all frequencies from 0.002 to $0.21 / \mathrm{hr}$ high-amplitude anomaly is manifested in the low frequency region. Begins forerunner in the low frequency region in March 0304 at the frequencies $0.0020 .0041 / \mathrm{hr}$ and reaches a maximum in March 1213, where there are frequency components $0.02-0.031 / \mathrm{hr}$. In the period from 14.03 to 18.03 low frequency component decays smoothly. Then comes the earthquake $K=14.5$. In the MF range $0.02-0.12$ 1/hr between March 0911 has been a surge of frequency components with a maximum at a frequency 0.04 1/hr. 6 days splash repeated with renewed energy and reaches a maximum at a frequency of $0.161 / \mathrm{hr}$. 
patterns of bioplasmaprecursors of earthquakes have been identified objectives of two active seismically regions of Kazakhstan.

In addition, branches operate the Central Station. One of them in the Biology Department Kazakh National University. Al-Farabi in the study of biophysics, where is one of geoanomalies towards the south-east, northwest. Installed in small bioindicators of Delhi (India), in Serebryansk East Kazakhstan region (Southern Altai), as well as in Anzhero-Sudzhensk (Russian Federation, Kemerovo region) and California (USA). With the slight weight indicators seismic hazard managed to capture fluctuations geoplasma before weak earthquakes on the west coast of the USA. Picture of changes in the amplitude of potentials geoplasma near the city of San Francisco is shown in Figure 2. As seen curve graph has splash February 13, 2005 the amplitude was $20 \mathrm{mV}$. After the seismic event February 17, 2005 significant fluctuations geoplasma not happen until March 21, 2005. Similar results were obtained when testing an indicator of seismic hazard in India [3]. A series of devastating earthquakes that occurred in the south-west of the country, were predicted for 10 - 15 days before they start. At the same time it is necessary to develop a fundamentally new biophysical technique in the detection of fluctuations geoplasma before the earthquake.

Figure 2 shows that small mass bioindicators, weighing not more than 2 pounds, who used to work in expeditions require replacement shell, insulation and live weight. Under the influence of extreme changes in temperature, ionizing radiation from natural and artificial sources, mechanical effects (shock, sound waves, magnetic fields) violated the integrity of membranes, there is penetration of oxygen into the biomass. As a result of increasing the formation of oxidative processes in the form of a shell of oxides on the electrode surface. Seismic hazard indicators weighing more than 50 kilograms retain their biophysical constants for 10 years of observation. Service needs radical modernization, the development of fundamentally new biological indicators with a high degree of stability and selectivity of perception of earthquake precursors. There are projects to develop indicators of seismic hazard of up to 100 tons, which will have Polyvectorbioretseptory capable of recording the most subtle changes in the structure of the electric charges and the real physical vacuum.

Each branch and central station must be equipped with radio communication and computer technology for instant information about the accumulation of precursors of earthquakes that will determine the starting date of the earthquake within a few hours. Moreover, such an upgraded service provides 100 percent information about whether or not seismic tremors in the city that will avoid panic among the population, which may occur after 5 6 magnitude earthquake, which can be regarded as a foreshock, according to the classical methodology of seismic.

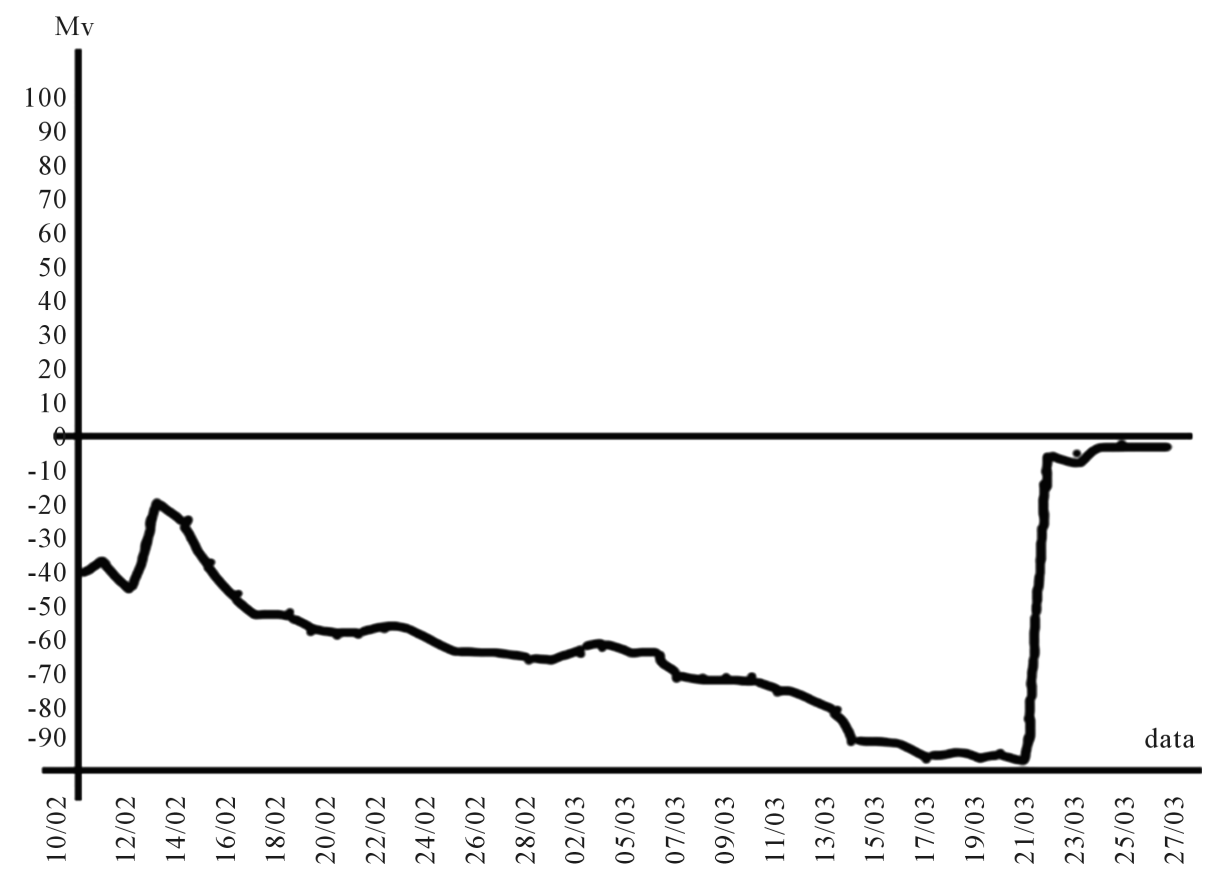

Figure 2. Geoplasma dynamics in California (USA) from February to 27 March 2005. 


\section{Radio Signals, Which Have the Ability to Abnormal Proliferation}

On the basis of the central station and the biophysical ecology KazNU conducted research on the electrical structure geoplasma and its connection to the ionosphere, which is of interest to obtain information about the precursors of earthquakes at various points of the Eurasian continent. So, as an instrument used by radio signals that scientists have shown how our University (V.Kanevsky, Gorbunov) have the ability to abnormal proliferationshown in Figure 3. With anomalous radio can determine the location of the future earthquake for dozens of hours before. Table 1 shows the effectiveness of certain new approach to the determination of the localization of the earthquake [4].

Analysis of the data suggests that the biophysical radiophysikal sensing future earthquake epicenters is a promising direction for the medium-term and short-term forecasting of seismic events. I believe that it is necessary to create an international network of seismic monitoring biophysical for all seismically active areas of the globe. Information about biophysical precursors of earthquakes should be accumulated in the computer center,

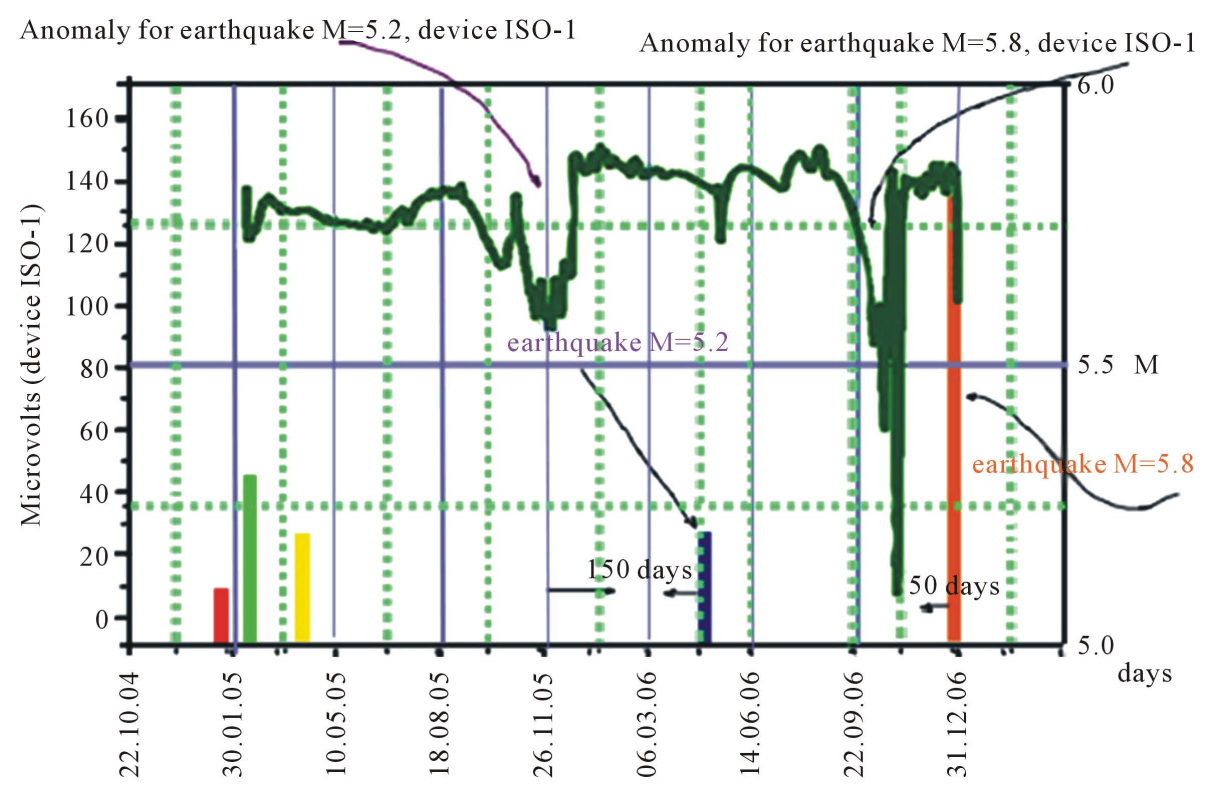

Figure 3. The ratio of the measured time series bioplasmic in 2005 to 2006. (green line) and earthquakes $(\mathrm{M}>5)$ occurred during this period. On bioplasmic curve observed two distinct peaks: the first corresponds to $M=5.2$ earthquake, 28.04.2006 (latitude, 41.71, 80.7, longitude), and the second harbinger, $\mathrm{M}=5.8$ earthquake, 25.12.2006 (42.16 latitude-longitude76.16). For the first earthquake waiting time is about 150 days. For the second 50 days.

Table 1. Definition of localization of future earthquakes anomalous conductivity radio.

\begin{tabular}{|c|c|c|c|}
\hline № & $\begin{array}{c}\text { Identification signals, conjugate } \\
\text { geophysical zones. Date and } \\
\text { vremyaregistratsii (vremya Almaty) }\end{array}$ & $\begin{array}{l}\text { Localization of the future earthquakes } \\
\text { (geographical area) }\end{array}$ & $\begin{array}{c}\text { Sostoyavshiesyazemletryaseniya } \\
\text { (localization, date ivremya days, } \\
\text { times GMT) }\end{array}$ \\
\hline 1 & 11.03.2004 г. 16:00 Bukhara & District Tajik-Afghanborder & $\begin{array}{c}12.03 .2004 \text { г. } 22: 45 \text { in the mountains } \\
\text { of Afghanistan (Hindu Kush) }\end{array}$ \\
\hline 2 & 02.06.2004 г. 00:11 Togliatti & District of Southern Iran & $\begin{array}{l}\text { 04.06.2004 г. 20:37 Iran and North } \\
\text { 11.06.2004 11:02 AM Southern Iran }\end{array}$ \\
\hline 3 & 03.08. 2004 г. 01:26 Moscow & Area Arabian Sea & 19.08.2004 г. 13:51 Arabian Sea \\
\hline 4 & 16.09.2004 г. 18:55 Bratsk & District of Sichuan Province and Kashmir & 23.09.2004 г. 17:28 Tibet \\
\hline 5 & 11.10.2004 г. 18:25 Bukhara & $\begin{array}{l}\text { Hindu Kush (Afghanistan) on the border } \\
\text { with Kashmir-Xinjiang Uygur } \\
\text { Autonomous Region. China }\end{array}$ & $\begin{array}{c}\text { 12.10.2004 г. 18:37 Xinjiang and } \\
\text { AR 15.10.2004 6:40 Hindu Kush, } \\
\text { Afghanistan }\end{array}$ \\
\hline
\end{tabular}


and operating information transmitted to all peripheral seismic monitoring station biophysical and services Ministry of Emergencies. In conclusion, I emphasize the value of such a centralized system of control over the "breath" of the Earth for the prevention and the prevention of industrial accidents in the mines, road transport, large power plants, etc.

The difference in amplitude corresponds to the difference in predictive power of earthquakes and definitely related to the distance to the point of registration.

So from the beginning there is a "biozemletryasenie" in Bioplasm (geoplasma) species and only after a very substantial period of time (for which you can thoroughly prepare for the upcoming disaster) comes the release of energy in the earth's crust (catastrophe).

\section{Time Series Analysis Bioplasmic Precursors of Earthquakes Recorded Instrument SHI-5 (Sesmicheskoy Hazards Indicator), in 2010 and 2012}

Long-term studies of biophysical earthquake precursors leave no doubt that the biosensors developed at the Department of Biophysics and Biomedical Kaz. NSU record PP (hereinafter abbreviated as "earthquake precursors") with a high degree of certainty. Biophysics give almost monthly forecast earthquakes in the months ahead shown in Figure 4 and Figure 5. This report focuses on a detailed assessment of the PP, which are registered device SHI-5 (3) in 2010 and 2012 [5].

In the frequency range $0.0001-0.00021 / \mathrm{h} \mathrm{n}$ biophysical isolated precursor of earthquakes that started 11.09. 2010 This harbinger for 5 months of observation has not yet peaked. Further observations will answer the question-when will the earthquake.

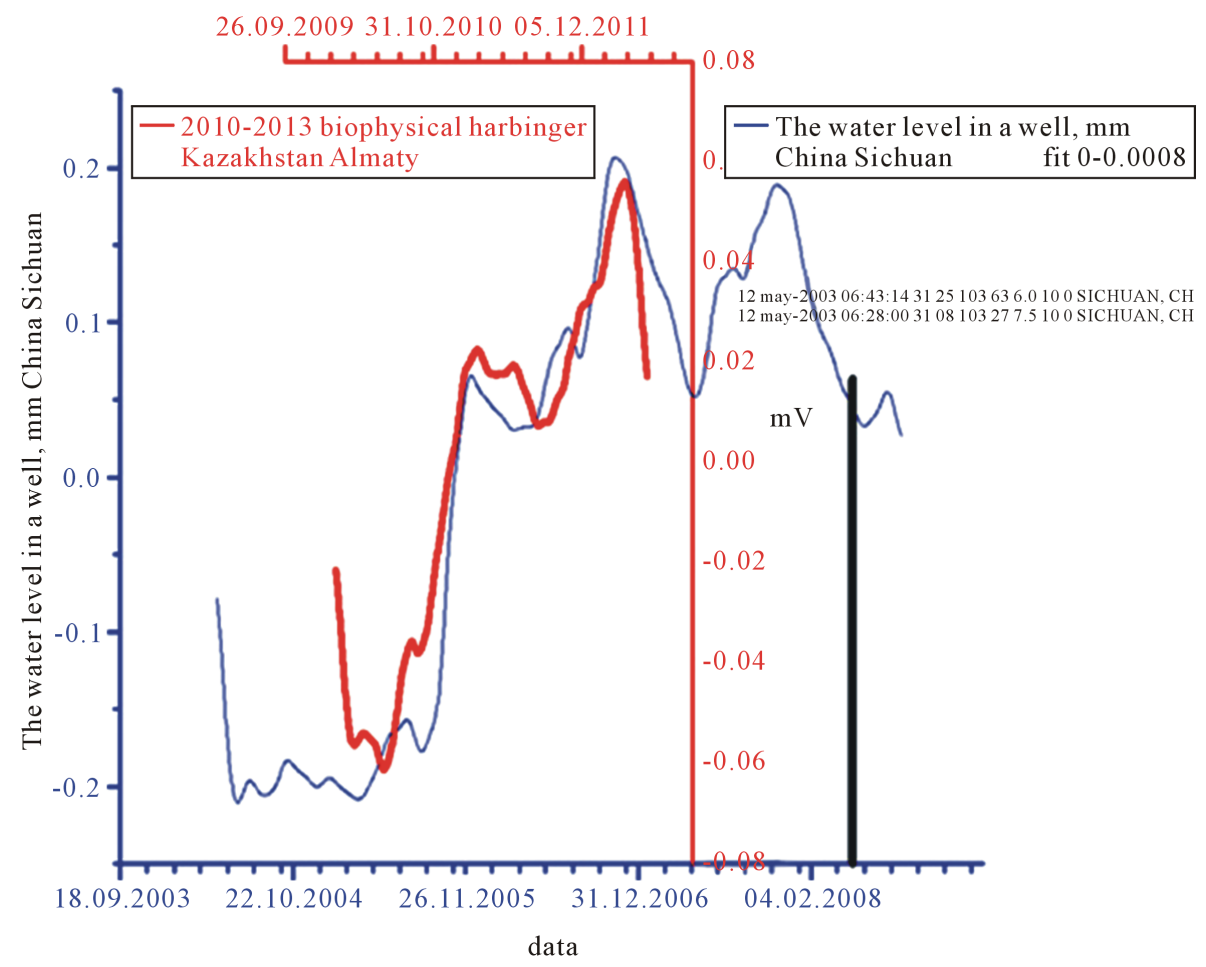

Figure 4. Characteristic of the time series are anomalies nizznochastotnogo PP composition. Each PP has its own frequency of exposure. PP was used to isolate low-pass filter (1). On this chart compares the low-frequency components for the SHI-5 device and the device measuring water in the province urovin Sychyuan (link will predostvlena in another paper). Deformation anomaly predicts Vynsyuanskoe earthquake began three years before the real break the crust. Obviously skhodstao harbinger of the biophysical and deformation. Beforehand, we can conclude that Alma oblyasti can be a disaster similar vynsyuanskoy. Filters were chosen according to the analysis of quasi-harmonic component is calculated by a strange attractor in the frequency domain. (SAW). 


$$
Z
$$




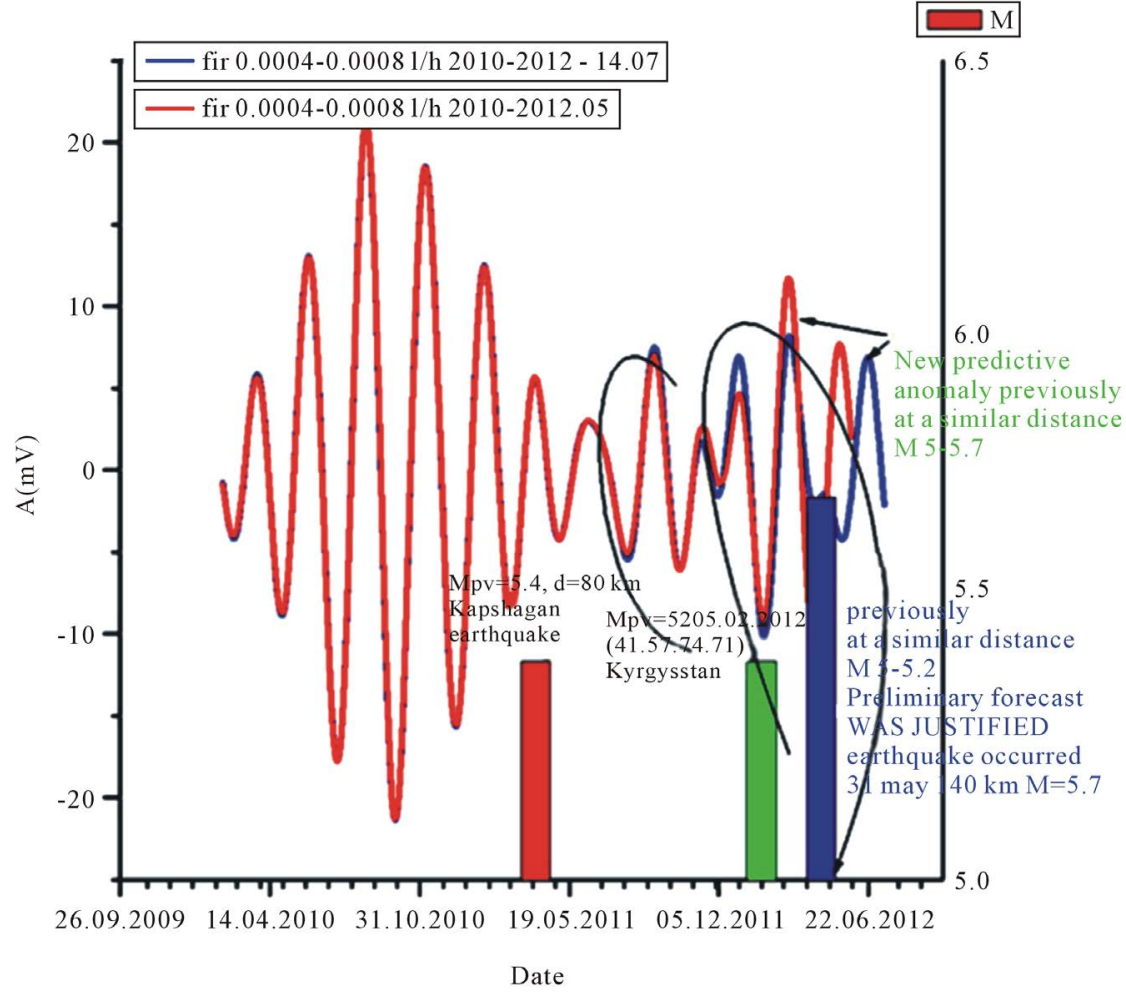

Figure 7. This was a harbinger sgenirirovan previous earthquake. All PP for $M \geq 5.0$ and distances from the registration point less $300 \mathrm{~km}$ have a fractal shape and, most importantly real earthquake occurs after the full attenuation anomalies precursor. And from start to finish anomaly precursor takes months.

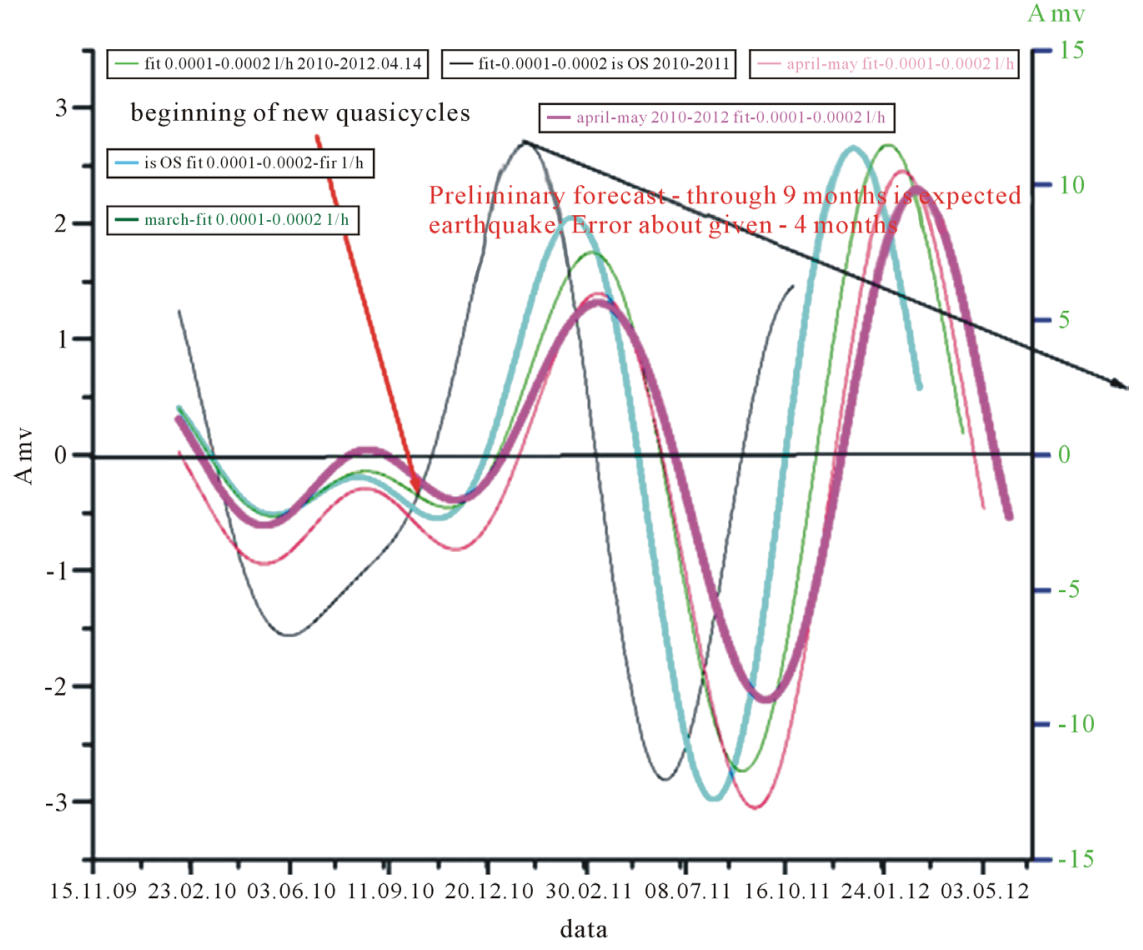

Figure 8. Filtering time series PP band 0.0032 - 0.0064 1/hour. 
PP in Figure 6 appeared in the 0.0004 - 0.0008 band 1/h. Magnitude 5.4. corresponds Kapshagan earthquake shown in Figure 7. Public monitoring has been carried out after the earthquake. All who posseschaet this side for five months could supervise the preparation of the earthquake in Almaty region, which occurred in $140 \mathrm{~km}$ from Almaty, $\mathrm{M}=5.7$. Monitoring is carried out monthly. And every month anomaly precursor form had its form and its peculiarities. Only 15 days anomaly fully formed and took final shape, fully damped. As has been repeatedly stated by me: Calamity originally proyavlyaets in geoplasma-Bioplasm and only after full decay occurs a real earthquake. PP in Figure 8 fully confirm my theory of earthquake prediction.

Next time series corresponds to a new earthquake precursor, Figure 6.

\section{Conclusions}

Precursors of earthquakes in the local bioplasmic field have been identified according to analysis. Not all anomalies were divided due to insufficient and irregular sampling of the original time series bioplasma. Nevertheless earthquake in Almaty region was opredelnie 5 months was up to the actual event.

Make a prediction of a future earthquake is preliminary. To verify the prediction must be registered biolazmennye time series to date. All the conditions have been upgraded, which create instruments and digital converters. And many lives will depend on these devices are connected or not.

\section{References}

[1] Inyushin, V.M. Il’yasov, G.U. and Nepomnyashchikh, I.A. (1991) Bioenergy-Structure Theory and Practice. Almaty.

[2] Inyushin, V.M. (1997) Bioplasm Cold Plasma and Earth. Al-Farabi Kazakh National University, Almaty.

[3] http://yug-kz.com/refr.htm

[4] http://www.kzyug.com/refer.html

[5] http://gu55dakz.yug-kz.com/devicepred.htm 